\title{
Top of Rail friction control for curve noise mitigation and corrugation rate reduction
}

\author{
D.T. Eadie ${ }^{*}$ and M. Santoro \\ Kelsan Technologies Corp., 1140 West $15^{\text {th }}$ St., North Vancouver, B.C., Canada \\ Tel: 604-984-6100, Fax: 604-984-3419,E-mail:deadie@kelsan.com
}

\begin{abstract}
Top of rail Friction Modifiers are designed to control frictional characteristics at the wheel-rail interface that influence noise, corrugations, and lateral forces. Key characteristics of the resulting thin film are 1) controlled intermediate coefficient of friction and 2) positive friction, to reduce rollslip oscillations related to both curve squeal noise and short pitch corrugation development. Practical results are presented on the effect of friction modifiers on curve squeal and flanging noise generation at a range of European mass transit sites. Noise reductions ranging from 6.3 to $22.8 \mathrm{dBA}$ were recorded, with an average reduction across the different test sites of $12.0 \mathrm{dBA}$. Both top of rail squeal and flanging components of noise were reduced.
\end{abstract}

The effect of friction modifier on short pitch corrugation development was evaluated over several years at two curves at Metro Bilbao. Under conditions where corrugations grew from 0.01 $\mathrm{mm}$ to $0.05 \mathrm{~mm}$ in eighteen months under baseline conditions, with application of friction modifier essentially no corrugation growth occurred in an equivalent time period.

\section{Introduction}

Railway noise in curves continues to be an area of concern. Both top of rail squeal and flanging noise are associated with curves, particularly sharp curves $(\mathrm{R}<500 \mathrm{~m})$, whereas rolling noise is generally associated with tangent track. "Roaring rail" is a noise phenomenon associated with the development of short pitch corrugations, also frequently occurring in curves.

Curve squeal originates from the unstable response on a wheel subject to large creep forces when negotiating a curve. Frictional instability in the form of stick-slip oscillations (more accurately referred to as roll-slip) excite a wheel resonance; the wheel vibration radiates noise efficiently. The accepted model involves top of rail frictional instability under lateral creep conditions leading to excitation of out of plane wheel bending oscillations. These are radiated and heard as squeal. The starting point for squeal is lateral creep forces that occur as a bogie goes through a curve and the wheel / rail contact patch becomes saturated with slip (creep saturation). A critical component is the requirement that, beyond the point of creep saturation, further increases in creep levels lead to progressively lower coefficient of friction. This is known as negative friction, referring to the slope of the friction creep curve at saturated creep conditions. This leads to roll-slip oscillations between the wheel and the rail which excite a wheel resonance, and the wheel web radiates the noise [1,2 and references therein].

The origins of corrugations are complex; the current state of knowledge in this area has recently been reviewed by Grassie [3]. Corrugation is considered as requiring both a "wavelength-fixing 
mechanism" and a "damage mechanism". Roll-slip oscillations due to frictional instability have been considered as a source of instability that can promote short pitch corrugations $[4,15]$. As with noise, the underlying cause of roll-slip is the negative friction characteristics of the wheel-rail interface.

The frictional characteristics of the wheel-rail interface are determined by the material properties of the so-called "Third Body", the layer of materials between the wheel and rail [12]. The use of top of rail friction modifiers to control the frictional characteristics of the wheel-rail interface is an emerging technology. Early results on noise control were reported by Eadie et al [7]. The effect of friction modifiers on the spectral noise characteristics in curves for different wheel rail systems has been described [2]. The effect of friction modifiers on reducing lateral forces and rail wear in heavy haul freight has also been reported [8]. Friction modifiers have achieved significant acceptance for curve noise control in North America and Asia (particularly Japan), with more than one hundred installed sites. Introduction of this technology on European railroads is at an earlier stage.

The potential role of top of rail friction modifiers in corrugation prevention has recently been highlighted by Grassie [3], and the basis for this approach discussed by Eadie et al. [4]. Recent results in this area in Japan have also been presented [5, 6].

This paper describes recent results on the effect of top of rail friction modifiers on noise levels and corrugation development on curves on a range of European mass transit systems. Spectral frequency changes are reported and discussed for five systems. Results are presented on changes in corrugation development rates with friction modifier from several years of testing at Metro Bilbao in Spain.

\section{Friction Modifier Characteristics}

Top of rail friction modifiers have two key characteristics relevant to noise and corrugation control:

1. Provision of a dry film with an intermediate coefficient based on the inherent material properties of the friction modifier in combination with the other Third Body components.

2. Provision of positive friction characteristics, meaning an increase in friction levels with increasing creep level.

The top of rail friction modifier used in this work is a water-based liquid material known as $\operatorname{KELTRACK}^{\mathbb{B}}[9,4$, and 7] which can be applied to the railhead by a number of different means. After water evaporation, the thin dry film that provides a coefficient of friction of $0.35+/-0.05$ as measured by a Salient Systems push tribometer. The differences between a true friction modifier and a lubricant have been reviewed [10]. Friction levels measured on rail for this material have been previously reported [8].

The positive friction characteristics of the friction modifier thin film have been established in several two roller rig studies $[11,6]$. The resulting frictional behaviour at the wheel-rail interface is the result of the combined material properties of both the friction modifier and the other Third Body components. The friction modifier has been designed for optimal interaction with the iron 
oxide wear components that dominate the Third Body under normal conditions. The film characteristics have also been developed so the film lasts for as many axles as possible.

\section{Experimental}

\subsection{Sound measurements}

Sound level measurements were carried out using a Bruel \& Kjaer 2260 Sound Level Meter. The microphone was fitted with a foam windscreen and handheld on the outside (high rail side) of the test curve. The sound meter was placed $7.5 \mathrm{~m}$ from the center of the track, with the microphone $1.2 \mathrm{~m}$ above the height of the rail. The exception was System 3, where local site constraints led to measurements $16 \mathrm{~m}$ from the track centre, $7.5 \mathrm{~m}$ above the rail. The maximum sound level range was pre-set to between 65 and $130 \mathrm{~dB}$ for train passes (35-100 dB for ambient). Sound measurements were made in the center of the curve. The sound level meter was programmed for event recording, enabling the instrument to automatically measure and stores the event data. The logged data was downloaded via a serial interface to a laptop computer. Sound level data reported is the averaged $\mathrm{LA}_{\mathrm{eq}}$ values for each of several trains under the particular conditions evaluated, the A weighted average sound level. Measurements were made during the residence time of the train in the curve. For trams, the residence time was approximately 15 seconds, for Metros about 30 seconds. Five or more trains were measured and the data reported is the average for all the trains measured.

\subsection{Friction modifier application}

For System 1 testing, a Portec Rail Protector IV unit was used for automatic application of friction modifier [13]. For tests on Systems 2-5, the liquid friction modifier was applied manually to the top of both rails using a paint roller. A target manual application rate is 0.34 grams per metre of rail (to each rail). Typically the friction modifier is applied to about $15 \mathrm{~m}$ of rail, of which half is in the tangent prior to the curve, and the remainder in the initial part of the curve. The purpose is to simulate automated application from a trackside applicator where the unit is placed in the tangent before the curve, and the film is carried down by the wheels into the body of the curve. However manual application differs from automated trackside application in that a constant film thickness is applied through the curve; with trackside application film thickness decreases with distance from the application bars.

For the corrugation test the friction modifier was applied using a Portec Rail Protector III automated trackside applicator. An outline of this equipment has been reported [13] which is an earlier version of the Protector IV.

\subsection{Corrugation measurements}

Corrugation characteristics were measured using an Esveld RAILPROF [14]. The instrument measures both vertical and lateral rail geometry without making mechanical contact. Two sensors are located inside the housing and driven by a step motor. Measurements are taken every $5 \mathrm{~mm}$ over a length of $1000 \mathrm{~mm}$. The trend at each point is the mean value over a length of $10 \mathrm{~cm}$ on either side. The positive and negative slopes are the steepest ascending and descending points of the trend. Short waves are the difference between the profile and the trend. The average amplitude is 
based on short waves, and is defined as the average of the maxima minus the average of the minima.

\section{Results}

\subsection{Noise}

Noise test results are presented from five representative sites in Europe. Pertinent site and vehicle characteristics are detailed in Fig 1, together with summary average noise data. These examples are chosen to represent a cross section of European systems, covering different countries, system types, rail condition, curvature etc.

\begin{tabular}{|c|c|c|c|c|c|}
\hline SYSTEM NUMBER & 1 & 2 & 3 & 4 & 5 \\
\hline Country & Spain & Italy & Spain & Netherlands & United Kingdom \\
\hline System Type & Metro & Tram & Light Rail & Tram & Tram \\
\hline Curve Radius, m & 220 & 25 (est.) & 250 & 25 & 26 \\
\hline Speed, kph & 50 & 5 to 10 & 65 & 10 to 15 & 15 \\
\hline Axle per car & 4 & 8 & 4 & 8 & 6 \\
\hline Cars per train & 6 & 1 & 6 & 1 & 1 \\
\hline Rail Type/Wt & UIC 54 & AP4N Phoenix Type & UIC 54 & RI 59 & $41 G$ \\
\hline Brake Type & Disk & Disk & Disk & & Disk \\
\hline Gauge face lubrication & Onboard oil & Onboard oil & Onboard oil & Trackside oil & Onboard oil \\
\hline $\begin{array}{l}\text { Friction modifier } \\
\text { Application method }\end{array}$ & Automatic trackside & Manual & Manual & Manual & Manual \\
\hline Ave LAeq Baseline (dBA) & 101.4 & 92.9 & 80.4 & 86.7 & 98.2 \\
\hline $\begin{array}{l}\text { Ave LAeq friction } \\
\text { modifier (dBA) }\end{array}$ & 95.1 & 83.1 & 72.5 & 73.3 & 75.4 \\
\hline Track Condition & Corrugated & Worn & Corrugated & Worn & New \\
\hline Track Structure & $\begin{array}{c}\text { Concrete } \\
\text { sleepers/ballast }\end{array}$ & Imbedded & $\begin{array}{c}\text { Concrete } \\
\text { sleepers/ballast }\end{array}$ & Imbedded & Imbedded \\
\hline
\end{tabular}

Fig 1: Site and vehicle characteristics from five test sites

The following points may be noted:

- In the absence of friction modifier there was significant curve noise at all sites.

- Average noise level reductions with friction modifier ranged from 6.3 to $22.8 \mathrm{dBA}$

- The average noise reduction across the different sites was $12 \mathrm{dBA}$.

- The smallest reduction occurred on a heavily corrugated system, where a large amount of the noise originated from the corrugations (System 1).

- Baseline noise is lower for System 3 because of the different measuring distances. In this system the noise is primarily top of rail related, with no flanging contribution.

- The largest noise reduction occurred on a recently opened tram system with severe squeal and flanging noise (System 5).

- All systems had some form of conventional gauge face lubrication for both baseline and friction modifier application. Clearly gauge face lubrication is ineffective for controlling noise in these curves.

- System 2 vehicles have independently rotating wheels. Only lateral creep forces are present in axles of this type (no longitudinal creep). Typical noise reduction with friction modifier was observed in this case. 
Figs 2 to 6 show the spectral change characteristics for the five systems with and without application of friction modifier. We have previously discussed the different spectral sound contributions of top of rail squeal and flange contact [2]. All systems show significant reduction in the spectral region primarily associated with top of rail squeal $(1000-5000 \mathrm{~Hz})$. In systems with a significant component from flanging noise, this was also noticeably reduced with the application of friction modifier. A good example of this can be seen by comparing baseline and friction modifier spectra for System 5 (Fig 6).

System 1 showed a significant noise component due to corrugations with a maximum at $200 \mathrm{~Hz}$. This maximum as expected did not change with application of friction modifier.

System 3 shows maxima at 500 and $800 \mathrm{~Hz}$ which are substantially reduced by application of friction modifier. Although the $500 \mathrm{~Hz}$ peak is lower than is usually associated with stick-slip related squeal, we speculate that this is also related to stick-slip because of the noticeable reduction that occurred. There was essentially no flanging noise at this site to the ear, and correspondingly there are no spectral components above $3150 \mathrm{~Hz}$ either in the baseline or with friction modifier.

The UK tram system (System 5, Fig 6) exhibits pronounced maxima at 630, 1600 and $4000 \mathrm{~Hz}$, all of which are eliminated or greatly reduced with the application of friction modifier.

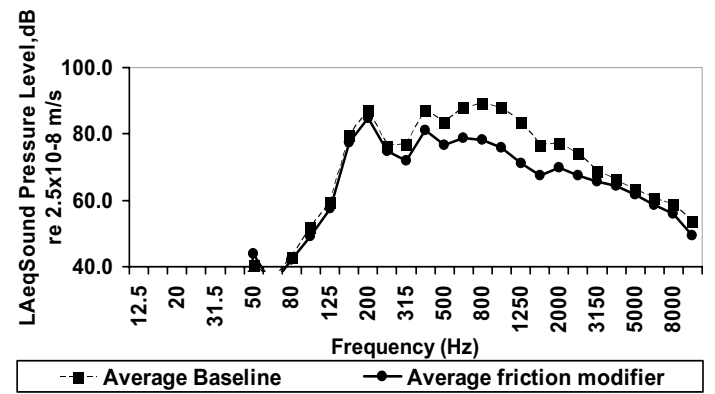

Fig 2, System 1: Spectral change characteristics

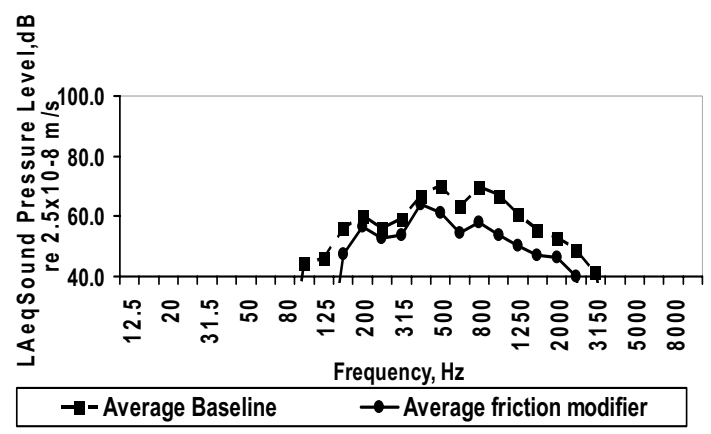

Fig 4, System 3: Spectral change characteristics

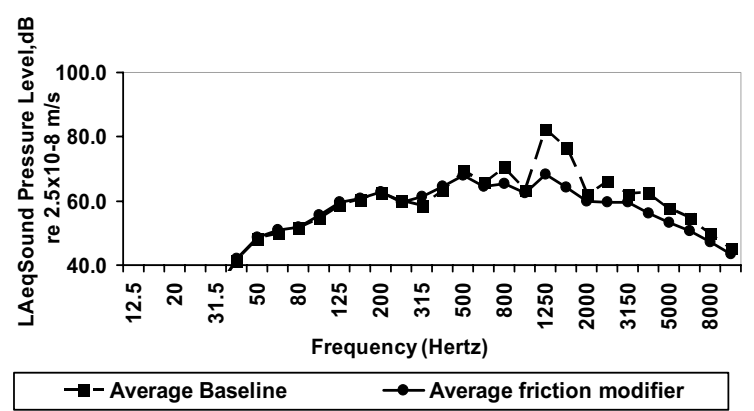

Fig 3, System 2: Spectral change characteristics

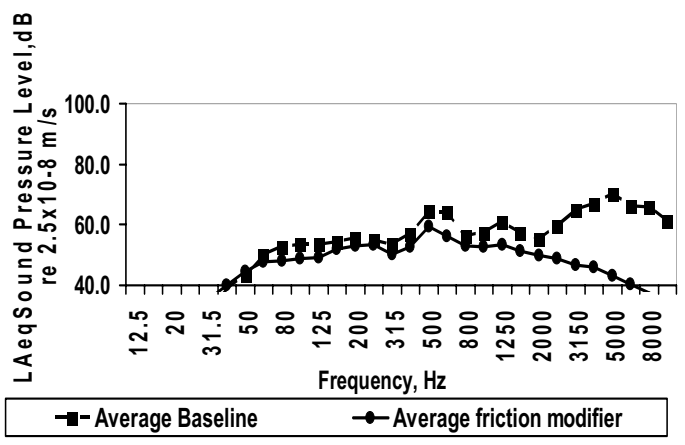

Fig 5, System 4: Spectral change characteristics 


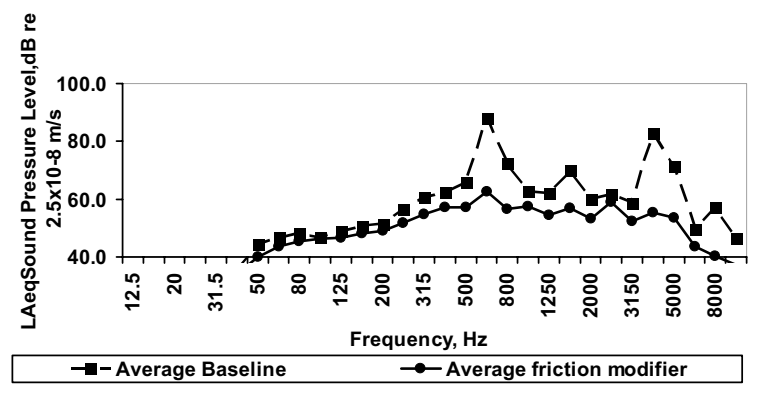

\subsection{Corrugation}

Fig 6, System 5: Spectral change characteristics

The corrugation rate test was carried out over several years at metro bilbao, in Bilbao, Spain. The line was first opened in November 1995 and has since had two extensions. Characteristics of this Metro system are listed in Fig 7.

\begin{tabular}{|c|c|}
\hline Rail size & UIC 54 \\
\hline Gauge, $\mathrm{cm}$ & $100 \mathrm{~cm}$ \\
\hline Wheel diameter, $\mathrm{mm}$ & 840 (new) to 770 (worn) \\
\hline Sleeper spacing, $\mathrm{cm}$ & 100 \\
\hline Vehicle type & $\begin{array}{c}\text { CAF 4 axle metro, four vehicle } \\
\text { per train }\end{array}$ \\
\hline Traction & All axles \\
\hline
\end{tabular}

Fig 7: Characteristics of metro bilbao

The goal of the trial was to monitor and document the amplitude of corrugations, starting from the point where the rail had been freshly ground, with and without friction modifier application. The ideal means of carrying out a corrugation trial is to compare results under precisely the same conditions with only one variable changed. This is often difficult to do in practise. However in this case, this ideal was achieved. No other significant change in track or vehicle characteristics occurred between baseline conditions and friction modifier application.

Monitoring of corrugations was carried out on two separate curves, for baseline conditions and friction modifier application. The characteristics of the two test curves are contained in Fig 10. The primary test was on a curve on Aiboa Track 1, with typical ballast structure. Additional useful results was obtained on Algorta Track 2 with concrete slab structure.

The corrugations generated by normal operation on the Aiboa test curve are shown in Figs 8 and 9. It can be seen that these are typical short pitch corrugations, with wavelength around $50 \mathrm{~mm}$. 


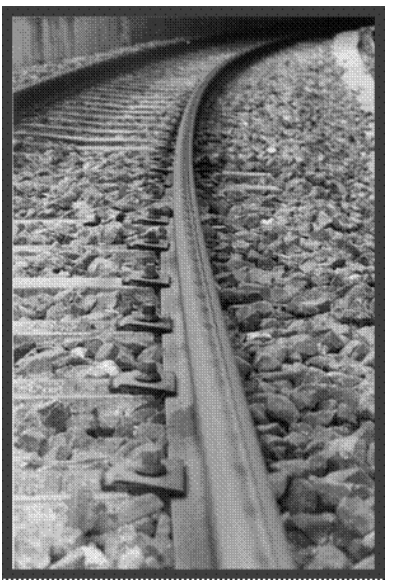

Fig 8

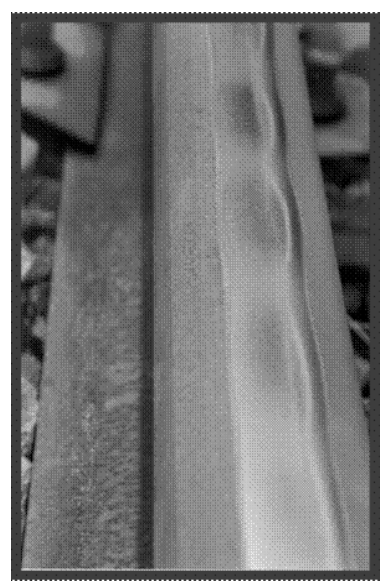

Fig 9

\begin{tabular}{|c|c|c|}
\hline $\begin{array}{c}\text { Curve } \\
\text { name }\end{array}$ & $\begin{array}{c}\text { Aiboa } \\
\text { Track 1 }\end{array}$ & $\begin{array}{c}\text { Algorta } \\
\text { Track 2 }\end{array}$ \\
\hline Radius, $m$ & $197.5 \mathrm{~m}$ & 155.5 \\
\hline Cant, $\mathrm{mm}$ & 110 & 120 \\
\hline Track & Ballast & Slab \\
\hline $\begin{array}{c}\text { Speed, } \mathrm{kph} \\
\text { Acceleration } \\
\text { m/s }\end{array}$ & $40-65$ & $40-60$ \\
\hline Grade, $\%$ & 1.15 & 1.15 \\
\hline
\end{tabular}

Fig 10: Curve characteristics of two test sites

Corrugations generated by normal operation

\subsubsection{Aiboa Track 1 test curve}

Results from corrugation monitoring at the Aiboa site are shown in Fig 11.

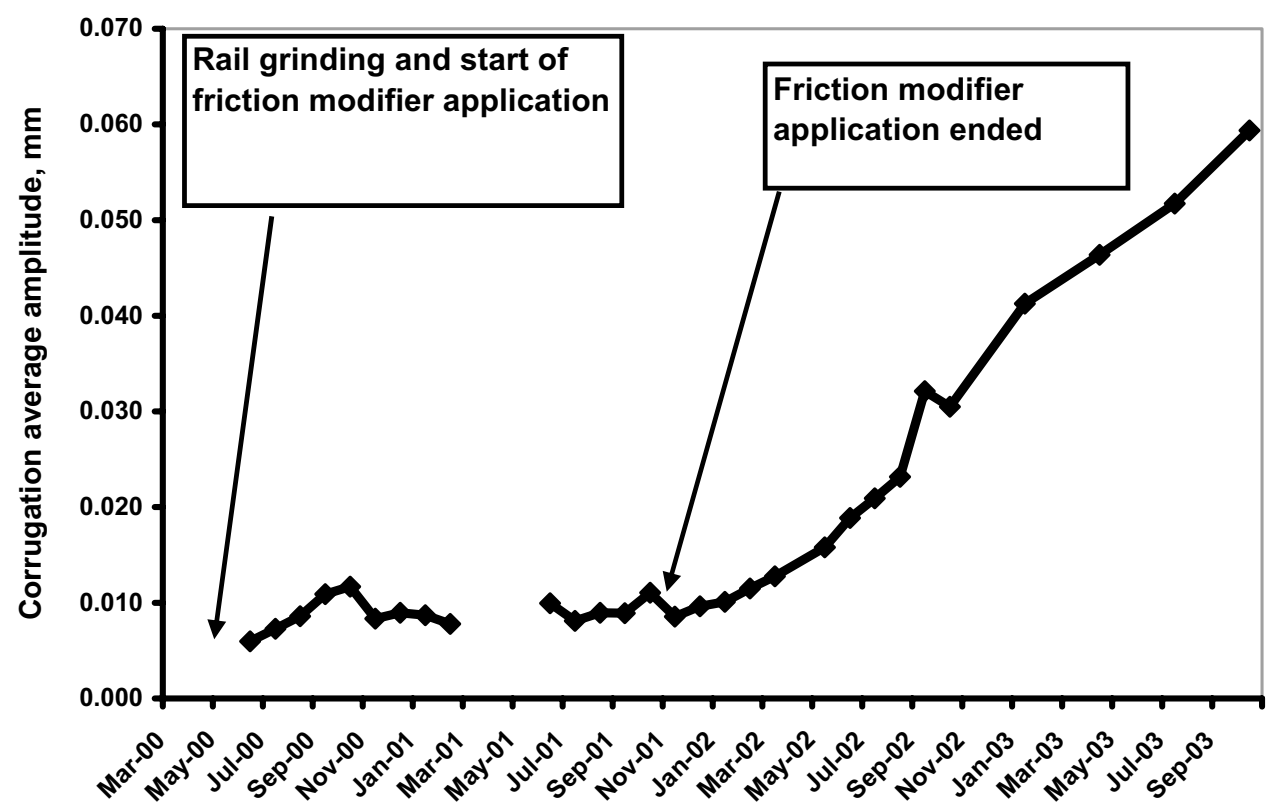

Fig 11: Corrugation monitoring Aiboa site

Aiboa Track 1 test curve location is at the exit from Aiboa station. The Protector equipment for applying the top of rail friction modifier was installed in March 2000, and in May 2001 the rail was ground, giving initial corrugation amplitude measurements around $0.005 \mathrm{~mm}$. Friction modifier application commenced after grinding. The friction modifier was applied continuously until November 2001 (approximately eighteen months). Very little growth in corrugation occurred in 
this time, with average corrugation amplitude of only $0.01 \mathrm{~mm}$ at the end of the period. At this point the application equipment was relocated, and "baseline" corrugation conditions monitored. No other significant changes were made to track or vehicle conditions for the baseline condition compared to the friction modifier period. Fig 11 shows that corrugation growth started almost immediately after the ending of friction modifier application. After eighteen months, corrugation amplitude for baseline conditions had increased to almost $0.05 \mathrm{~mm}$.

\subsubsection{Algorta test curve}

Fig 12 shows corrugation results for the other test curve (Algorta Track 2).

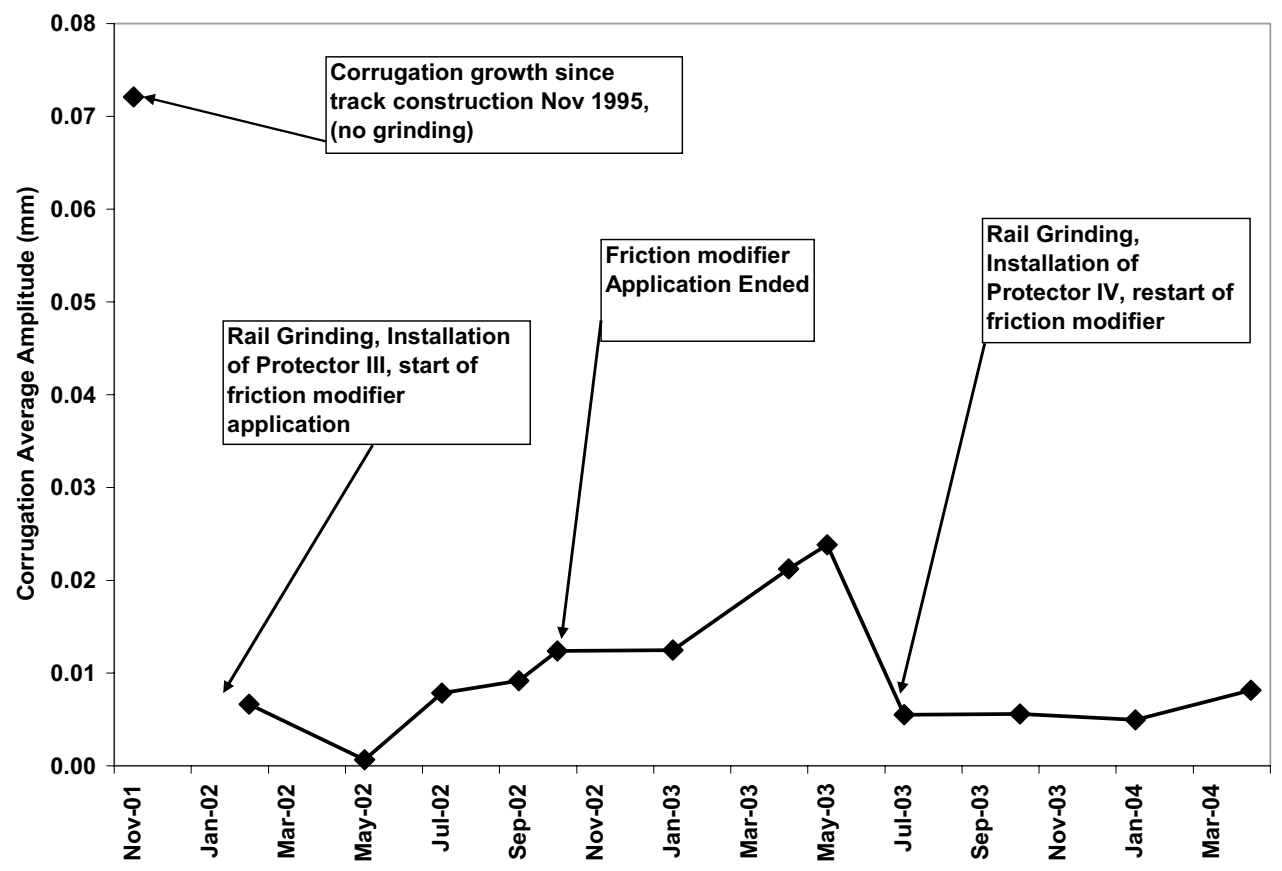

Fig 12: Corrugation results at the Algorta Track

This track was originally installed in 1995. There was no grinding between the original installation and March 2002. In November 2001 corrugation amplitude was measured at more than $0.07 \mathrm{~mm}$. Friction modifier application was commenced in March 2002 after rail grinding. Initial corrugation depth was $0.008 \mathrm{~mm}$. Corrugation amplitude was monitored for a period of nine months until December 2002. Corrugations had changed little, increasing in this period to $0.013 \mathrm{~mm}$. The unit was shut off due to mechanical failure at this time. Monitoring of corrugations continued ("baseline" conditions). The removal of the friction modifier application resulted in an immediate growth of the corrugation amplitude. In a period of five months the average amplitude increased to from $0.013 \mathrm{~mm}$ to $0.025 \mathrm{~mm}$.

The track was ground again in July $2003(0.05 \mathrm{~mm})$. A Protector IV applicator was installed at the same location on Algorta Track 2, and friction modifier application recommenced. Fig 12 shows that there was no growth in corrugation amplitude for the seven months of application.

The data at Algorta is less clear cut than that from Aiboa, because the base line period with full data is less than idea. However the results here also suggest that the friction modifier has substantially reduced the rate of growth of corrugations at this site. Monitoring is continuing at this site. 


\section{Discussion}

\subsection{Noise}

The results presented in this paper support previous data indicating that top of rail friction modifiers can provide significant noise reduction in curves. A range of representative European curves with noise problems has been evaluated, and in each case significant noise reduction recorded with friction modifier application.

We have observed that top of rail squeal noise tends to be concentrated in the region 1000 to $5000 \mathrm{~Hz}$, and flanging noise shows spectral characteristics primarily in the range 5000 to $10000 \mathrm{~Hz}$ [2]. Friction modifiers can reduce both of these noise sources in curves. The reduction in top of rail noise is thought to occur primarily through the provision of positive friction characteristics to the $3^{\text {rd }}$ Body in the wheel-rail interface, thus reducing the roll-slip oscillations [4]. Flanging noise reduction, however, occurs through an indirect mechanism. By reducing top of rail friction in a controlled fashion, both lateral and flanging forces are reduced, thereby reducing the noise associated with flange contact. This mechanism is supported by the observed reduction in high rail gauge corner wear that has been recorded even when friction modifier is applied only to the top of the low rail [8].

\subsection{Corrugation}

The use of friction modifiers has been described as a promising new tool for effectively controlling short pitch corrugation growth in curves [3]. Several previous publications have suggested the effectiveness of friction modifier for corrugation control. However none of these specifically quantified the reduction in the rate of corrugation growth. In some previous trials it was also not possible to separate the effect of friction modifier from other system changes made simultaneously [15].

The results in this paper firmly establish the very significant reduction in corrugation growth rates in curves that can be achieved with friction modifiers, under well controlled conditions. This reduction in corrugation growth will clearly translate to a significant reduction in noise, or to a reduction in the requirement for grinding for noise control. Where wheels are smooth, it has been estimated that badly corrugated track can lead to noise increases up to $20 \mathrm{~dB}$ [16].

\section{Future Directions}

The use of friction modifiers for curve noise control is now well established through this and previous papers. Ongoing work is continuing to further quantify the effect of friction modifiers on corrugation growth rates with different corrugation types, and to translate this to noise reduction. Other areas under current investigation are the influence of friction modifiers on rolling contact fatigue crack initiation and propagation.

Our goals for the future include defining the influence of friction modifiers on the rate of roughness growth on both wheels and rail in tangent and curves, and relating this to rolling noise. Collaboration proposals in these areas are welcomed. 


\section{Acknowledgements}

We would like to thank José Manuel Fernández and his colleagues at the Technical Office of metro bilbao in Bilbao, Spain for carrying out the measurements of the effect of friction modifier on corrugation growth rates. Their careful attention to detail and pioneering efforts are gratefully acknowledged and recognized.

We would like to thank Ed Bovey and Felix Susaeta for their many contributions to the metro bilbao corrugation testing. The assistance of Neil Harvey in carrying out the sound measurements on Systems 4 and 5 is also acknowledged.

\section{References}

[1] D. J Thompson, A.D. Monk-Steel, C. J.C. Jones, P. D. Allen, S. S. Hsu and S. D. Iwnicki, Railway Noise: Curve Squeal, Roughness Growth, Friction and Wear, Rail Research UK Report RRUK/A3/1, June 2003, available at http://civ-hrg.bham.ac.uk/RailResearchUK/theme-a3.htm

[2] D.T. Eadie, M. Santoro and J. Kalousek, Railway Noise and the Effect of Top of Rail Liquid Friction Modifier, Proceedings of the $6^{\text {th }}$ International Conference on Contact Mechanics and Wear of Rail/Wheel Systems (CM2003), Vol. II, Gothenburg, Sweden, June 10-13, 2003, pp. 503-510

[3] S. L. Grassie: Rail Corrugation, Advances in Measurement, Understanding and Treatment, Proceedings of the $6^{\text {th }}$ International Conference on Contact Mechanics and Wear of Rail/Wheel Systems (CM2003), Appendix I, Gothenburg, Sweden, June 10-13, 2003, pp. 11-19

[4] D.T. Eadie, J. Kalousek \& K. S. Chiddick, The role of high positive friction (HPF) modifier in the control of short pitch corrugations and related phenomena, Wear Vol. 253, 1-2, July 2002, pp. 185-192

[5] Y. Suda, T. Iwasa, H. Komine, M. Tomeoka, H. Nakazawa, K. Matsumoto, T. Nakai, M. Tanimoto and Y. Kishimoto, Development of On Board Friction Control System, Proceedings of the $6^{\text {th }}$ International Conference on Contact Mechanics and Wear of Rail/Wheel Systems (CM2003), Vol. II, Gothenburg, Sweden, June 10-13, 2003, pp. 321-326

[6] Y. Suda, T. Iwasa, H. Komine, T. Fuji, K. Matsumoto, N. Ubukata, T. Nakai, M. Tanimoto, Y. Kishimoto, The Basic Study on Friction Control between Wheel and Rail (Experiments by test machine and scale model vehicle), Proceedings of the $6^{\text {th }}$ International Conference on Contact Mechanics and Wear of Rail/Wheel Systems (CM2003), Vol. II, Gothenburg, Sweden, June 10-13, 2003, pp. 343-348

[7] D.T. Eadie, M. Santoro \& W. Powell: Local control of noise and vibration with KELTRACK ${ }^{\mathrm{TM}}$ friction modifier and Protector ${ }^{\circledR}$ trackside application: an integrated solution, Journal of Sound and Vibration, Vol. 267, Issue 3, October 23, 2003, pp. 761-772

[8] D.T Eadie, N. Hooper, B. Vidler \& T. Makowsky: Top Of Rail Friction Control, Lateral Force And Rail Wear Reduction In A Freight Application, International Heavy Haul Conference, Dallas, May 4-8, 2003

[9] K. S. Chiddick: Solid Lubricants \& Friction Modifiers for Heavy Loads and Rail Applications, US Patent No. 6,136,757, October 24, 2000.

[10] D.T. Eadie \& J. Kalousek: Spray it on, let 'em roll, Railway Age, June 2001, p.48

[11] A. Matsumoto, Y. Sato, H. Ono, Y. Wang, M. Yamamoto, M. Tanimoto, Y. Oka: Creep force characteristics between rail and wheel on scaled model, Wear, Vol. 253, Issues 1-2, July 2002, pp 199-203

[12] K. Hou, J. Kalousek, and E. Magel: Rheological model of solid layer in rolling contact, Wear, Vol. 211, Issue 1, October 1997, pp.134-140

[13] http://www.portecrail.com

[14] http://www.esveld.com

[15] J. Kalousek and K.L. Johnson: An investigation of short pitch wheel and rail corrugations on Vancouver mass transit system" Proc. Inst. Mech. Engrs, Vol. 206, Part F: Journal of Rail and Rapid Transit, 1992, pp. 127-135

[16] A.E.J. Hardy and R.K.K. Jones: Rail and wheel roughness - implications for noise mapping based on the Calculation of Railway Noise procedure, AEA Technology Report AEATR-PC\&E-2003-002, March 2004, pp.167, available at www.defra.gov.uk/environment/noise/rail-mapping/pdf/railway-noise.pdf 